
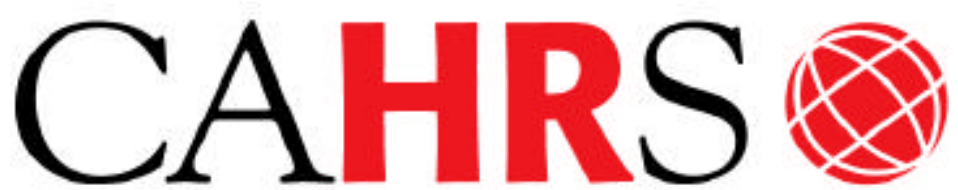

Center for Advanced Human Resource Studies
CAHRS / Cornell University 187 Ives Hall

Ithaca, NY 14853-3901 USA

Tel. 607 255-9358

www.ilr.cornell.edu/CAHRS/

\title{
Open Door Policies: Measuring Impact Using Attitude Surveys
}

S. Antonio Ruiz-Quintanilla Donna Blancero

Working Paper $95-26$ 


\title{
Open Door Policies: Measuring Impact Using Attitude Surveys
}

\author{
S. Antonio Ruiz-Quintanilla \\ Center for Advanced Human Resource Studies \\ ILR School/Cornell University \\ Ithaca, NY 14853-3901 \\ (607) 255-5927 \\ Donna Blancero \\ Department of Management \\ College of Business \\ \& Hispanic Research Center \\ Arizona State University \\ Box 874006 \\ Tempe, AZ 85287-4006 \\ (602) 965-3431
}

Working Paper 95-26

Draft: Comments Welcomed and Encouraged

www.ilr.cornell.edu/cahrs

This paper has not undergone formal review or approval of the faculty of the ILR School. It is intended to make results of research, conferences, and projects available to others interested in human resource management in preliminary form to encourage discussion and suggestions. 


\begin{abstract}
This study examines employee perceptions of an Open Door Complaint System from both those who have filed claims and those who have not. Our sample includes over 4000 employees working in a Fortune 100 company. We examine these perceptions through an organization wide employee attitude survey. Analyzing situation specific perceptions, we examine their relationship with overall fairness, satisfaction and intent to remain with the organization. Results suggest that a positive Open Door incident raises both distributive and procedural justice perceptions. In turn, fairness perceptions influence satisfaction levels. Finally, results indicate that satisfaction has a strong effect on the intent to remain with the organization. Implications are discussed for both complaint systems and employee opinion surveys.
\end{abstract}


Businesses and researchers have been increasingly interested in studying nonunion complaint systems. Several studies focus on the consequences of giving employees the right or opportunity to express their opinions, referred to as voice effects of these systems (Aram \& Salipante, 1981; Blancero, 1992; Boroff 1991, 1994; Ewing, 1989; Klaas \& Feldman, 1994; McCabe, 1988; Peterson \& Lewin, 1990; Westin \& Feliu, 1988). In fact, a recent issue of Employee Responsibilities and Rights Journal (March 1994) was devoted specifically to the examination of managerial third party resolution. While estimates vary, approximately fifty percent of all medium- and large-sized organizations have formalized non-union complaint systems (Delaney, Lewin \& Ichniowski, 1989; Ewing, 1989; McCabe, 1988; Peterson, 1994; Peterson \& Lewin, 1990; Westin \& Feliu, 1988). Studying the fairness, or efficacy, of these systems and why these systems may or may not be perceived as fair is one stream of research. However, as Greenberg (1990a \& 1993) has suggested, the study of fairness needs to go beyond the description of antecedents of fairness perceptions.

While field data in this realm are difficult to obtain, given the sensitive nature of these systems, perceptions of voice and non-union complaint systems may have significant implications for organizations. Perceptions of fairness may accrue and have a "reputation building effect" (Greenberg, 1987), i.e., individuals exposed to a series of procedurally fair events may be more likely to accept occasional unfavorable decisions, or outcomes. Acceptance of unfavorable decisions may result in decreased "unhealthy" organizational behaviors, such as employee theft (Greenberg, 1990a \& b). Moreover, research has suggested that perceptions of fairness can lead to perceptions of job satisfaction (Alexander \& Ruderman, 1987; Greenberg, 1990a). In turn, job satisfaction can lead to decreased turnover (Arnold \& Feldman, 1982; Bluedorn, 1982; Dailey \& Kirk, 1992; Hollenbeck \& Williams, 1986; Mobley, 1982; Porter \& Steers, 1973; Tett \& Meyer, 1993). A good source for obtaining, and subsequently examining, data regarding these perceptions surrounding complaint systems may be from employee attitude surveys.

Through our work at the Center for Advanced Human Resource Studies (CAHRS) we have found that virtually all of our sponsors use employee attitude surveys, in some fashion. Many companies have standardized reports issued quarterly, or semi-annually, that provide descriptive statistics for various perceptions or attitudes. These include issues such as satisfaction and fairness, and often additionally probe into attitudes related to pay and benefits or a specific human resource program. Typically, these data collections remain constant over a period of time, although questions on new issues may cycle in and out, as necessary. 
We think that there is a multitude of information in these surveys that may be untapped. Human resource interventions, or programs, such as complaint systems, affect employees' perceptions and attitudes. This study examines employee perceptions of the voice/nonunion complaint system, that of an "Open Door" procedure, utilizing an organization's employee attitude survey. Only through a collaboration between researchers and managers could the existing, but untapped, information in the attitude survey be exploited to reveal the significant effects of the Open Door system on employee feelings and work behaviors. We examine perceptions and attitudes of over 4400 employees of this Fortune 100 company. For those employees who have personally used the complaint system, the evaluations of their specific experiences are examined as well, and overall perceptions are compared between "filers" and "non-filers". These attitudes include procedural justice, distributive justice, job satisfaction, and employees' intentions to remain with their organization. Figure 1 illustrates the major elements and relationships of our research model. This model will be elaborated in the following paragraphs. 
Figure 1: Research Model

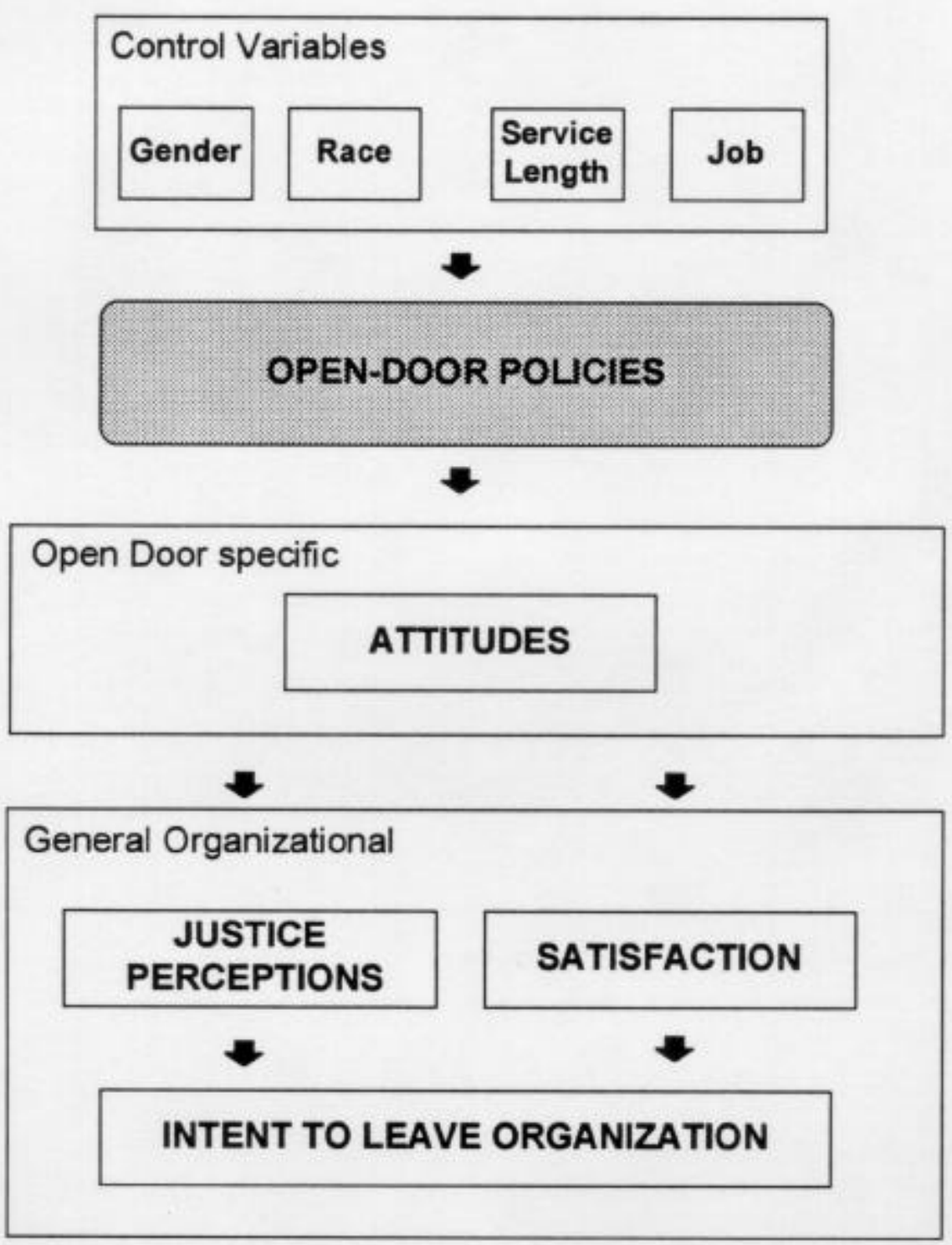




\section{Non-union complaint systems and fairness}

Establishment of non-union complaint systems has grown over the past two decades. Many types of grievance systems exist, including the Open Door system, which may be the most common (Balfour, 1984). The number of organizations who have recently established complaint systems has increased over the past decade (Delaney, Lewin \& Ichniowski, 1989; Ewing, 1989; McCabe, 1988; Peterson \& Lewin, 1990; Westin \& Feliu, 1988) and estimates are that approximately 50 percent of all medium and large companies have systems in place (Delaney, Lewin \& Ichniowski, 1989). Additionally, the number of organizations that may currently be considering the establishment of such a system has increased over the past decade (Delaney, Lewin \& Ichniowski, 1989; Ewing, 1989; McCabe, 1988; Peterson \& Lewin, 1990; Westin \& Feliu, 1988). Several characteristics of non-union complaint systems may lead to fairness: the level of employee input into the process, the perceived impartiality of the decision maker, the timeliness of the system, and, of course, the actual outcome (Aram \& Salipante, 1981; Blancero, 1992; Boron 1991; Ewing, 1989; McCabe, 1988; Rowe \& Baker, 1984; Westin \& Feliu, 1988).

Fairness, or organizational justice, is typically examined via either distributive justice or procedural justice. Distributive justice refers to the fairness perceptions based on an outcome, or allocation of resources, while procedural justice perceptions are based on the processes used to make the decision about allocations (Folger \& Greenberg, 1985). Thus, while distributive justice is centered on the "ends," procedural justice focuses on the "means."

In a complaint system, employees' distributive justice perceptions would be formulated based on the result or outcome of their complaint. In other words, if employees "win" their case, or in some way feel that they received what they wanted, or deserved, they would likely perceive that distributive justice was attained. The process that employees go through, from initiating the complaint through to the final resolution, form the basis for perceptions of procedural justice. Theory guides us in this area quite well. Research has suggested that the availability of voice allows a sense of process control, and hence heightens perceptions of procedural justice (Bies \& Shapiro, 1988; Folger, 1977; Folger \& Greenberg, 1985). In this sense "voice" can be defined as the amount of input employees have into the process. Process control, which is the perceived control one has over the process, can manifest itself in an Open Door system by the amount of input the employees have as well as the perception of impartiality of the decision maker. Clearly, individuals who have used the Open Door system will have perceptions of the system based on their specific experiences. Based on their perceptions of the 
voice allowed them during the process, these "filers" will evaluate the procedures; this evaluation will, in turn, be associated with perceptions of procedural justice.

Additionally, the evaluation of the interaction may affect interpersonal justice, a component of procedural justice. Interpersonal justice expands on the concept of interactional justice, which is the perception of justice based on the interpersonal interaction (Bies \& Moag, 1986). Greenberg (1994) has further expanded the definition of interactional justice, and categorizes it into either interpersonal justice, which is the degree of sensitivity and concern showed an individual or informational justice, which is the adequacy of the information provided. Both of these may be considered part of procedural justice (Greenberg, 1994).

H1 Perceptions regarding the perceived interpersonal justice of the Open Door process will be positively associated with overall perceptions of procedural justice.

This first hypothesis expresses the reputation building effect of experiences, mentioned earlier. We expect that employees who have used the system, and who had a positive experience with the interpersonal justice aspect of their complaint, will have increased perceptions of procedural justice. In this sense, as explained later in the methodology section, procedural justice is a broad concept of the fairness of procedures in general in the organization.

Clearly, by the very definition of distributive justice, employees' evaluations of their specific incidents with the Open Door system will be related to their overall perceptions of distributive justice.

H2 Evaluation of an Open Door outcome will be positively associated to the overall perceptions of distributive justice.

This second hypothesis examines both an overall or general perception of distributive justice on the part of the employee, i.e., not specific to their complaint incident, and the specific perception. So, we are expecting their specific outcome to affect their overall, broader perception of distributive justice in the organization. Moreover, if an employee uses the Open Door system and has either a positive outcome (i.e., "wins"), or a positive interpersonal perception, it also follows that the employee will have a positive attitude, overall, towards the Open Door system

H3 The perceived interpersonal justice of a specific Open Door process will be positively associated with the overall attitude toward the Open Door System. 
H4 The evaluation of an Open Door outcome will be positively associated with the overall attitude toward the Open Door system.

In turn, attitudes regarding the Open Door system, which include issues such as retaliation, will affect fairness perceptions. For those who used the system, their attitudes will be based on a combination of their specific incident and their observation of others. For those who did not use the system, their perceptions will come primarily from observation of fellow workers who have used the system. Of course, their perceptions may also generalize from their experiences with other processes in the organization.

Finally, some evidence supports that there is a frustration effect when it comes to procedures, i.e., that some people reject procedures that appear to offer process control but don't provide any real input into the decision making process (Folger, 1977; Lind, Kanfer \& Earley, 1990). This effect may be the result from either an unsuccessful personal experience with the system, or merely an observance of the system, resulting in a perception that the system is unfair, or lacks credibility (Aram \& Salipante, 1981; Rowe \& Baker, 1984). Thus,

H5 Perceptions of the Open Door system, for both filers and non-filers, will be positively associated with overall perceptions of fairness. This includes fairness associated with procedures (procedural justice) and fairness of outcomes (distributive justice).

Different explanations of how individuals make the decision to evaluate procedural justice have been suggested (Greenberg, 1990a). While strong evidence exists to suggest that procedural justice moderates the relationship between outcome and distributive justice (Blancero, 1992; Greenberg, 1987; Lind et al., 1980). In other words, if the process is perceived to be fair, individuals will perceive their outcome to be fair. While research exists to support this, research also exists to support the theory that the outcome can affect the perception of procedural justice (Fryxell \& Gordon, 1989; Greenberg, 1987, 1990a; Lind, Kanfer \& Earley, 1990). Given the importance of Open Door system issues to employees, we think the second explanation is more appropriate for us to consider with this research. Thus, when an outcome is favorable to an individual, the perception of the process will also be favorable to that individual. Alternatively, when the outcome is not favorable, the process will be evaluated as less favorable. Following this logic, one can expect that the interpersonal justice perceptions (based on a specific situation) will be related not only to procedural justice, as discussed above, but also related to the situation specific evaluation of the outcome. Further, the same may be true for the broader procedural justice and distributive justice. 
H6 Therefore, specifically, the evaluation of the outcome of the Open Door event will be positively related to the situation specific perception of interpersonal justice.

H7 In a more general way, overall perceptions of procedural justice will be positively associated with overall perceptions of distributive justice.

In other words, if employees have a positive outcome for their complaint, they will also tend to feel positive regarding the process. In the general sense, if one perceives outcomes to be fair, it follows that the process used to get to those outcomes must have also been fair.

Although it may be argued that evaluations of the Open Door system are somewhat ephemeral and thus, less meaningful, others have shown that even short lived affective reactions can have serious impacts on organizational behaviors (Greenberg, 1994). Given that experiences with complaint systems, in this case an Open Door system, can be very important to employees, it is expected that these perceptions will be long lived. Either extreme --- a positive process and a positive outcome, or a negative process and a negative outcome -- will likely have a strong effect on individuals' perceptions of procedural justice (Lind \& Tyler, 1988).

H8 Of those who use the system, individuals who have positive perceptions of both interpersonal justice (situation specific) and evaluation of outcome will have higher perceptions of procedural justice than those who do not use the system.

H9 Of those who use the system, individuals who have negative perceptions of both interpersonal justice (situation specific) nerd evaluation of outcome will have lower perceptions of procedural justice than those who do not use the system.

As indicated, fairness perceptions may have a long lasting effect. Research has suggested that perceptions of fairness can lead to job satisfaction (Alexander \& Ruderman, 1987; Greenberg, 1990a). Some research has looked at issues of trust and commitment, and suggested that procedural justice is associated more strongly with system satisfaction and distributive justice is associated more with the specific outcome satisfaction (Folger \& Konovsky, 1989). One study specifically examining organizational complaint systems has suggested that perceptions of procedural justice based on these systems are the foundation for broader organizational beliefs, such as the belief in a just workplace (Fryxell, 1992). Thus, while both procedural and distributive justice may be positively associated with satisfaction, previous research suggests that procedural justice will be more strongly associated.

H10a Perceptions of procedural justice will be positively associated with perceptions of job satisfaction. 
H10b Perceptions of distributive justice will be positively associated with perceptions of job satisfaction.

H10c Procedural justice will explain more variance in job satisfaction than will distributive justice.

There has been an enormous amount of research regarding job satisfaction, much of it regarding the antecedents of this attitude. Research strongly supports the finding that job satisfaction leads to higher intentions to remain with the organization (Arnold \& Feldman, 1982; Bluedom, 1982; Dailey \& Kirk, 1992; Hollenbeck \& William, 1986; Mobley, 1982; Porter \& Steers, 1973; Tett \& Meyer, 1993). In fact, a recent meta-analysis (Tett \& Meyer, 1993) suggests that satisfaction correlates more strongly with withdrawal cognition than does commitment. Moreover, the intent to turnover is the strongest predictor of actual turnover (Lee \& Mowday, 1987; Michaels \& Spector, 1982; Steel \& Ovalle, 1984; Tett \& Meyer, 1993).

H11 Perceptions of job satisfaction will be positively correlated with intent to remain with the organization.

\section{Methodology}

Sample and Procedures

Data represent a portion of the Fortune 100 company data base. This company conducted monthly surveys of representative samples of their workforce on a wide array of issues since 1984. Researchers from CAHRS and company representatives agreed on sharing the database from June 1984 to December 1992 for research purposes. Data tapes, questionnaires and other documentation material for the 90 data files were exchanged. Data files were transformed to SPSS standard and checked for readability, missing values, and errors like out of range codings. In addition a data cleaning program was developed and applied, that checked for inconsistencies across questions (e.g. employee's age minus 14 years should be greater than length of service with company). Next, all data files were prepared for merging, e.g. same questions got assigned the same variable name, answer alternatives where checked for same coding. All data files were merged and a table showing which questions were asked at which point in time was developed. Using this table, sets of recurring questions were identified and used for scale development. Questions involving the issue of interest here, those evaluating the companies Open Door policies, were asked in the summer of 1985 (June, July, and August) and the summer of 1987 (June, July, and August). During all these steps frequent interactions 
between CAHRS researchers and company representatives ensured the required exchange of additional background information.

As mentioned, all data were collected from a sample of employees at a Fortune 100 Company. Questionnaires were distributed by the company's research survey department, filled out during working hours and returned anonymously. The distribution of the questionnaires was conducted in a manner to ensure a representative distribution among all employees of the company. Sampling was done without replacement so that no employee responded more than once over the course of two years. The total number of respondents was 4460 (2206 in 1985 and 2069 in 1987). About 88 percent of the respondents $(n=3928)$ had no missing values in items and were included in the following analysis.

\section{Measures}

\section{Attitudes towards the Open Door System}

Two items were included in both data collections (1985 and 1987), which allowed us to estimate the general attitude of employees towards the Open Door system. These data are available for both filers and non-filers. One item assessed the concept of retaliation, and asked whether the employee thought that using the Open Door system would lead to later disadvantages. The response alternatives ranged from 1 (definitely would suffer) to 4 (definitely would not suffer). The second item asked whether or not the respondents felt free to proceed with a complaint to someone higher, in case they were not satisfied with the answer from their immediate supervisor. The response option for this item was a 5-point scale, ranging from 1 (strongly agree) to 5 (strongly disagree). Both items were equally weighted and combined to form an index estimating attitudes towards the Open Door procedure.

Evaluation of the Open Door Outcome.

There were three items answered by employees who had used the Open Door system which allowed us to estimate their satisfaction with their outcomes. The first question asked about the specific results of their decision (1 very dissatisfied, $5=$ very satisfied). The second question asked whether they "suffered" as a consequence of using the Open Door system (1=yes, a great deal, 4=no, not at all). Lastly, the third question asked whether the employee would use the Open Door system again in a similar situation. Again, the items were equally weighted and combined into a measure of outcome evaluation. The alpha for the combined sample was.65 (.65 in 1985 and .66 in 1987).

\section{Perceived Interpersonal Justice of the Open Door Process}

For those who used the Open Door procedure, seven questions were asked to evaluate their specific interaction. On a five point scale from 1 (strongly disagree) to 5 (strongly agree) 
the employees evaluated whether: (1) people listened, (2) understood their concern, (3) treated them with respect, (4) responded to the complaint within a reasonable time, (5) kept the information confidential, (6) treated the respondents fairly and, (7) the general atmosphere of the meeting. These seven items were combined into a scale which has an alpha of. 86 for the combined sample (.85 in 1985 and .87 in 1987). Note that this measure is similar to empirically based, existing measures used for research purposes (e.g., Moorman, 1991). Thus, while this measure is extracted from a corporate survey, it is comparable to existing measures.

Perceptions of Procedural Justice Regarding Performance Appraisals.

Procedural Justice was measured with a four item scale, and was answered by both filers and non-filers. These items queried employees about their perceptions of fairness of overall processes such as: (1) their performance being judged fairly, (2) their performance appraisal reflecting their contribution fairly, (3) their immediate supervisor being usually fair, and (4) their satisfaction with recognition for doing a good job. Answers were given using a five point scale ( $I=$ strongly disagree, $5=$ strongly agree). These items were combined into a scale; the alpha of the scale was .82 for the total sample (.80 in 1985 and .83 in 1987). Once again, this measure is comparable to other existing measures of procedural justice (e.g., Moorman, 1991; Moorman, Niehoff \& Organ, 1993).

Perceptions of Distributive Justice Regarding Pay.

Distributive Justice was assessed with four items, also using both filers and non-filers.. Questions were answered using a five point scale. The items referred to their perceptions of fairness associated with outcomes, such as: (1) the amount of their pay, (2) the comparison of their pay with people in similar jobs in other companies [for the first two questions $1=$ much lower and 5=rnuch higher], (3) whether they agreed that they were being paid fairly, and (4) generally agreeing that the company pays employees fairly [for the last two questions $1=$ strongly disagree and $5=$ strongly agree]. The alpha of this four item scale was.80 for the combined sample (.80 in 1985 and .79 in 1987). This measure is quite specific to fairness associated with pay. As well, similar to the other dimensions of fairness, it is not unlike existing measures.

Overall Satisfaction.

Five items in the questionnaire were used to assess respondents overall satisfaction, using the full sample of filers and non-filers. The items included; (1) satisfaction with their job in general, (2) overall satisfaction with the company at the present time, (3) satisfaction with involvement in decisions effecting their work, (4) satisfaction with opportunities to get a better job, and (5) the extent to which they liked their work. All items were answered using a five-point scale, with leery dissatisfied and 5wery satisfied. The alpha of this satisfaction scale was .82 for 
the combined sample (.82 in 1985 and .81 in 1987). Once again, while this measure comes from the corporate survey, it is not much different than existing satisfaction scales (i.e., MSQ used in research (Scarpello \& Campbell, 1983).

Intent to remain with the organization.

Four items were used to build a scale assessing employees' intentions to remain with the company. The items asked both filers and non-filers: (1) whether they thought they might still work for the same company within a year (1=certainly not, 5=certainly), (2) whether they view the company as a challenging work place ( $1=$ strongly disagree, $5=$ strongly agree), (3) whether they believe they can achieve a satisfying career with the company ( $1=$ strongly disagree, $5=$ strongly agree), and (4) asked them to rate the company by comparing it to other workplaces ( $\mathrm{I}=$ much worse than other places, $5=$ much better than other places). The alpha for this scale was .76 for the combined sample (.74 in 1985 and. 77 in 1987). This measure gets at turnover from a positive perspective (i.e., intent to remain rather than intent to leave). That aside, it is not unlike other measures of turnover (Schaubroeck, May \& Brown, 1994).

Inspection of our satisfaction" and "intent to remain" questions' wording seems to suggest that the two concepts overlap due to the way they are measured. Given that our scales are not established scales, but scales which were build from a survey questionnaire this critique has to be taken seriously. To check for a possible concept overlap we conducted a confirmatory analysis using LISREL 7 (Joereskog \& Soerbom, 1989) including all "satisfaction" and "intent to remain" questions for the total sample. A test for dimensionality showed that the data are better represented by a two factor model $(X Z=664, d f=26)$ as compared to a one factor solution $\mathrm{M}=1226, \mathrm{df}=27$ ). Goodness-of-fit indicators $(\mathrm{GFI}=.97, \mathrm{NFI}=.95, \mathrm{RMSEA}=.075)$ express a good fit of the two factor model to the data. For the two factor model, all items showed highly $(p<.001)$ significant t-values (ratio between estimate and its standard error) on the hypothesized dimension, which reflects that one can be confident that the corresponding question influences the dimension at issue.

Analysis

In our analysis we distinguish between independent and dependent variables related to our hypotheses and control variables. To examine the effects of the control and independent variables (evaluation of specific Open Door outcomes, perceived interpersonal justice of the Open Door process, general attitudes toward the Open Door system, procedural and distributive justices, and satisfaction), we used multiple regression analysis. In absence of a hypotheses about the causal order of effects, we decided to include all variables in a single step into the regression analysis and to apply the test function in SPSS for Windows to examine the 
magnitude of the effects of the control variables (gender, race, service length, and position) and the independent variables. To estimate the direct effects of each single control and independent variable on the dependent variables we examine the beta weights. In addition, we are interested in estimating the contribution of "sets" of variables to the explained variance, independent of all others. These "sets" or categories of variables will be further explained below.

The regression analyses were conducted for two samples: the sample of the filers alone, which includes two variables not in the total sample (evaluation of the Open Door outcome and the perceived interpersonal justice of the Open Door process), and the total sample of both filers and non-filers.

\section{Variable sets}

As control variables, we included gender, race, service length and position. We tested for the effect of these variables in two separate sets, one including gender and race (general demographics) and the second set examined service length and position, or occupational information. For the independent variables we also distinguished between two sets. The first one (Open Door specific perceptions) is related to the Open Door system, and includes one variable for the total sample "attitude towards the Open Door system" and the variables "evaluation of the Open Door outcome" and the "perceived interpersonal justice of the Open Door process" for filers only. The second set (general organizational perceptions) includes procedural justice, distributive justice, and satisfaction, for the full sample. Tables Three and Four summarize the results, providing beta values and significance levels for the single variables and the R-squared contribution of the four variable sets (general demographics, occupational information, Open Door specific perceptions, general organizational perceptions). Additionally, the total explained variance is illustrated for each equation.

\section{Results}

Tables One and Two presents the means, standard deviations, and correlations among the variables. 
Table 1: Means and Standard Deviations for filers and total sample

\begin{tabular}{|l|c|c|c|c|}
\hline \multirow{2}{*}{} & \multicolumn{2}{|c|}{$\begin{array}{c}\text { Filers } \\
\mathrm{N}=1406\end{array}$} & \multicolumn{2}{c|}{$\begin{array}{c}\text { Total Sample } \\
\mathrm{N}=3928\end{array}$} \\
\cline { 2 - 5 } & $\mathrm{X}$ & $\mathrm{S} . \mathrm{D}$. & $\mathrm{X}$ & S.D. \\
\hline Gender & & & & \\
0=male & $73.3 \%$ & & $75.6 \%$ & \\
1=female & $26.7 \%$ & & $24.4 \%$ & \\
\hline Race & & & & \\
0=Caucasian & $91.3 \%$ & & $91.2 \%$ & \\
1=Other & $8.7 \%$ & & $8.8 \%$ & \\
\hline Company Service length & 4.03 & 1.55 & 4.05 & 1.69 \\
1=<1 year & $.6 \%$ & & $2.4 \%$ & \\
$2=1-5$ years & $16.3 \%$ & & $17.5 \%$ & \\
$3=6-10$ years & $25.1 \%$ & & $22.4 \%$ & \\
$4=11-15$ years & $22.3 \%$ & & $20.4 \%$ & \\
$5=16-20$ years & $19.4 \%$ & & $18.2 \%$ & \\
6=21-25 years & $10.1 \%$ & & $11.5 \%$ & \\
$7=26-30$ years & $3.5 \%$ & & $3.8 \%$ & \\
8=31-35 years & $1.8 \%$ & & $2.6 \%$ & \\
9=>35 ears & $.9 \%$ & & $1.3 \%$ & \\
\hline Job high & & & & \\
0= other & $70.7 \%$ & & $63.3 \%$ & \\
1= manager, supervisor, professional & $29.3 \%$ & & $36.7 \%$ & \\
\hline Job low & & & & \\
0= other & $78.2 \%$ & & $80.8 \%$ & \\
1= sales, production, service & $21.8 \%$ & & $19.2 \%$ & \\
\hline Outcome evaluation en Door & 3.89 & .96 & & \\
\hline Interpersonal Justice en Door & 3.72 & .72 & & \\
\hline Attitudes Open Door & 3.08 & .98 & 3.12 & .92 \\
\hline Distributive Justice & 3.27 & .77 & 3.40 & .73 \\
\hline Procedural Justice & 3.21 & .92 & 3.43 & .87 \\
\hline Overall Satisfaction & 3.31 & .79 & 3.51 & .76 \\
\hline Intent to Remain & 3.86 & .70 & 3.97 & .67 \\
\hline
\end{tabular}


Table 2: Zero-Order Correlation among the variables ${ }^{12}$

\begin{tabular}{|c|c|c|c|c|c|c|c|c|c|c|c|c|}
\hline & 1 & 2 & 3 & 4 & 5 & 6 & 7 & 8 & 9 & 10 & 11 & 12 \\
\hline 1. Gender & & .05 & -.23 & -.17 & -.04 & .07 & .05 & 02 & .03 & .08 & .00 & .05 \\
\hline 2. Race & .09 & & -.07 & -.05 & .06 & -.04 & -.03 & -.01 & -.05 & -.05 & -.04 & -.04 \\
\hline 3. Service length & -.20 & -.09 & & .14 & -.02 & -.03 & .02 & .03 & .03 & -.02 & .02 & .08 \\
\hline 4. Job high & -.20 & -.08 & .15 & & -.34 & .01 & .02 & .06 & .02 & .02 & .09 & .03 \\
\hline 5. Job low & .02 & .08 & -.06 & -.37 & & .05 & .07 & -.01 & .04 & .02 & -.07 & .03 \\
\hline $\begin{array}{l}\text { 6. Outcome eval. } \\
\mathrm{OD}^{3}\end{array}$ & - & - & & & - & & .66 & .62 & .26 & .45 & .40 & .36 \\
\hline 7. Interp. Just. OD & - & - & & & - & - & & .49 & .25 & .37 & .32 & .29 \\
\hline 8. Attitudes $\mathrm{OD}^{3}$ & .00 & .00 & .06 & .12 & -.05 & & & & .26 & .43 & .40 & .35 \\
\hline 9. Distr. Justice & .01 & -.05 & .07 & .09 & -.01 & - & - & .27 & & .42 & .35 & .37 \\
\hline $\begin{array}{l}\text { 10. Proceed. } \\
\text { Justice }\end{array}$ & .05 & -.03 &. .0l & .11 & -.03 & - & - & .43 & .45 & & .59 & .47 \\
\hline 11. Satisfaction & -.01 & -.03 & .03 & .15 & -.08 & - & & .38 & .36 & .62 & & .65 \\
\hline $\begin{array}{l}\text { 12. Intent to } \\
\text { Remain }\end{array}$ & .021 & -.02 & $.05 \mathrm{I}$ & .061 & -.02 I & - & -1 & .361 & $.41 \mathrm{I}$ & 51 & & \\
\hline
\end{tabular}

$1 \quad$ Filers above the diagonal $(\mathrm{N}=1406)$, Total sample (filers and non-filers below the diagonal $(\mathrm{N}=3928)$

2 Significance levels for the filers (above the diagonal) are: $(r>.09>p$ tool) $(r>.07>p<01)(r>.0 S>p<.05)$

Significance levels for the total sample (below the diagonal) are: $(r>.05=>p$ tool) $(r>.04=>p<.01)(r>.03=>p<.05)$

$3 \quad$ OD $=$ Open Door 


\section{Control variables}

For the filers, we found a significant, although small (beta of .06) effect of gender on perceptions of procedural justice and on the intent to remain with the organization. In both cases, females tend to have higher values, thus suggesting that they perceive higher procedural justice and have a higher likelihood to remain with the organization, compared to males. There is no significant effect for race. These results are reflected in the figures for the R-squared contribution (Table Three) of the general demographic set, which is zero for all four dependent variables.

Table 3: Standardized Beta values and RZ-Changes for Regression Analysis predicting Intent to Remain, Satisfaction, Distributive and Procedural Justice for Open Door Filers $(\mathrm{N}=1406)^{\prime}$

\begin{tabular}{|c|c|c|c|c|}
\hline Variables & $\begin{array}{l}\text { Intent to } \\
\text { Remain }\end{array}$ & Satisfaction & $\begin{array}{l}\text { Distributive } \\
\text { Justice }\end{array}$ & $\begin{array}{l}\text { Procedural } \\
\text { Justice }\end{array}$ \\
\hline \multicolumn{5}{|l|}{ Control Variables } \\
\hline $\begin{array}{l}\text { Gender } \\
\text { Race }\end{array}$ & $\begin{array}{l}.06 * * \\
-.01\end{array}$ & $\begin{array}{l}-.04 \\
-.01\end{array}$ & $\begin{array}{r}.01 \\
-.03\end{array}$ & $\begin{array}{r}.06 \\
-.04\end{array}$ \\
\hline$\Sigma$ General demographic $\Delta \mathrm{R}^{2}$ & $.00 *$ & .00 & .00 & .01 \\
\hline $\begin{array}{l}\text { Service length } \\
\text { Job high } \\
\text { Job low }\end{array}$ & $\begin{array}{l}.08^{* * *} \\
-.01^{* *} \\
.07^{* *}\end{array}$ & $\begin{array}{r}.01 \\
.04 \\
-.08 * \star \star\end{array}$ & $\begin{array}{l}.03 \\
.01 \\
.03 \\
\end{array}$ & $\begin{array}{l}.00 \\
.02 \\
.02\end{array}$ \\
\hline $\begin{array}{l}\Sigma \text { Occupational information } \\
\Delta R^{2}\end{array}$ & $.01^{* * *}$ & $.01^{\star \star \star}$ & .00 & .00 \\
\hline \multicolumn{5}{|l|}{ Independent Variables } \\
\hline $\begin{array}{l}\text { Outcome eval. OD' } \\
\text { Interp. Just. OD' } \\
\text { Attitudes Open Door }\end{array}$ & $\begin{array}{l}.06^{*} \\
.00 \\
.05\end{array}$ & $\begin{array}{l}.10 * * * \\
.02 \\
.10 * * *\end{array}$ & $\begin{array}{l}.01 \\
.08 \text { * } \\
.07 \text { * }\end{array}$ & $\begin{array}{l}.24 \\
.09 * * \star \\
.24\end{array}$ \\
\hline$\Sigma$ Open Door specific $\Delta \mathrm{R}^{2}$ & .01 & .03 & .01 & .24 \\
\hline $\begin{array}{l}\text { Procedural Justice } \\
\text { Distributive Just. } \\
\text { Satisfaction }\end{array}$ & $\begin{array}{l}.05^{*} \\
.13^{* \star *} \\
.53^{* \star *}\end{array}$ & $\begin{array}{l}.45^{* * *} \\
.11^{* * *}\end{array}$ & $.35^{* \star \star}$ & \\
\hline$\Sigma$ General Organizational $\Delta \mathrm{R}^{2}$ & $.29^{* \star *}$ & $.19^{\star \star \star}$ & $.09^{* \star *}$ & \\
\hline Total R-S ware & .47 & .40 & .19 & .25 \\
\hline
\end{tabular}

${ }^{4}$ Significance levels: ${ }^{* * *} p<.001 ;{ }^{* *} p<.01 ;{ }^{*} p<.05$

${ }^{3} \mathrm{OD}=$ Open Door 
Table 4: Standardized Beta values and R2-Changes for Regression Analysis predicting Intent to Remain, Satisfaction, Distributive and Procedural Justice for the Total Sample $(\mathrm{N}=3928) 6$

\begin{tabular}{|c|c|c|c|c|}
\hline Variables & $\begin{array}{l}\text { Intent to } \\
\text { Remain }\end{array}$ & Satisfaction & $\begin{array}{l}\text { Distributive } \\
\text { Justice }\end{array}$ & $\begin{array}{l}\text { Procedural } \\
\text { Justice }\end{array}$ \\
\hline \multicolumn{5}{|l|}{ Control Variables } \\
\hline $\begin{array}{l}\text { Gender } \\
\text { Race }\end{array}$ & $\begin{array}{r}.02 \\
0.00\end{array}$ & $\begin{array}{l}-.03^{*} \\
.00\end{array}$ & $\begin{array}{l}.01 \\
-.04\end{array}$ & $\begin{array}{r}.07 \\
-.03\end{array}$ \\
\hline$\Sigma$ General demographics $\Delta \mathrm{R}^{2}$ & 0.00 & 0.00 & $0.00^{*}$ & $0.00^{\star \star \star}$ \\
\hline $\begin{array}{l}\text { Service length } \\
\text { Job high } \\
\text { Job low }\end{array}$ & $\begin{array}{l}.03^{\star} \\
-.04^{\star \star \star} \\
.02^{*}\end{array}$ & $\begin{array}{l}-.01 \\
.05 * * * \\
-.04 * *\end{array}$ & $\begin{array}{l}.06^{\star \star \star} \\
.03^{.02}\end{array}$ & $\begin{array}{l}-.01 \\
.08 * * * \\
.02\end{array}$ \\
\hline $\begin{array}{l}\Sigma \text { Occupational information } \\
\Delta R^{2}\end{array}$ & $.00^{* * *}$ & $.01^{\star \star \star}$ & $.01^{\star \star \star}$ & $.01^{\star * *}$ \\
\hline \multicolumn{5}{|l|}{ Independent Variables } \\
\hline Attitudes Open Door & $.09^{\star \star \star}$ & $.14^{\star \star \star}$ & $.09^{* \star \star}$ & $.42^{* \star \star}$ \\
\hline Open Door specific $\Delta \mathrm{R}^{2}$ & .01 & .02 & .01 & .17 \\
\hline $\begin{array}{l}\text { Procedural Justice } \\
\text { Distributive Just. } \\
\text { Satisfaction }\end{array}$ & $\begin{array}{l}.07^{\star \star *} \\
.16^{* \star *} \\
.53^{* \star *} \\
\end{array}$ & $\begin{array}{l}.52^{\star \star \star} \\
.09^{\star \star \star}\end{array}$ & $.40^{\star \star \star}$ & \\
\hline$\Sigma$ General Organizational $\Delta \mathrm{R}^{2}$ & .35 & .26 & .13 & \\
\hline Total R-Square & .49 & .42 & .21 & .19 \\
\hline
\end{tabular}

${ }^{6}$ Significance levels: *** $p<001 ;{ }^{* *} p<01 ;{ }^{*} p<.05$

These results are confirmed by the outcomes of the analysis for the total sample, shown in Table Four. Here we find only small effects for gender on procedural justice, and for race on distributive justice. Once again, the beta values are quite small (.07 and -.04, respectively). The direction of the effect for race indicates that non-whites tend to have lower distributive justice perceptions. The R-squared contribution of the general demographic control variables together is again zero for all four equations.

In the filers sample, the two occupational control variables -- length of service and occupational position (being at the lower end) -- have a significant effect on the intent to remain with the organization. Those who are employed with the company for a longer time and those who are at the bottom of the job hierarchy have higher intentions to stay with the company. Additionally, occupational position is negatively related to satisfaction. Other than this, the variables in this block show no further significant effect on satisfaction, distributive or procedural justices. The contribution of this set of variables to the explained variance remains small (.01), although significant for intent to remain, satisfaction, and procedural justice.

Comparing the variance contribution with the ones resulting for the total sample, we get similar results. The $\mathrm{R}$-squared changes for the occupational information items taken together 
remain small (.01), although for this sample, the R-squared change is significant in all four equations. Looking at the beta values for the single variables in the total sample, we find again mainly low effects (.08 and lower). Length of service is positively related to intent to remain and distributive justice. People at the top of the occupational hierarch have a lower intention to stay with the company, higher satisfaction, and tend to see the company procedures as fair when compared with those in lower positions. Those at the bottom of the occupational hierarchy tend to be less satisfied.

\section{Open Door related variables}

Having a positive perception of interpersonal justice during the Open Door process raises both the distributive and procedural justice perceptions towards the organization, supporting hypothesis one. However, their evaluation of the outcomes is significantly related to all variables but distributive justice. Hypothesis two, which suggested that the evaluation of the specific outcome would generalize to overall distributive, or outcome related, justice was not supported. Employees who evaluate the Open Door outcomes as positive have a stronger intention to remain with the organization, are more satisfied with the organization in general, and perceive it as procedurally just. The significant positive correlation between interpersonal justice and the overall attitude toward the Open Door system ( $r=.49)$ confirms hypothesis three (see Table Two). In addition, the high significant correlation between the evaluation of the Open Door outcome and overall attitudes toward the Open Door ( $\mathrm{i}=.62)$ supports hypothesis four (also in Table Two).

In addition, having a positive attitude towards the Open Door procedure is related with higher satisfaction, and a higher perception of both distributive and procedural justice within the organization, supporting hypothesis five. Standardized beta values for these variables tend to be higher (up to .24) when compared with the beta weights for the control variables. This is reflected in the changes of the R-squares, which are significant for Open Door specific item set in all four equations and range from .01 for intent to remain and distributive justice to .03 for satisfaction to .17 for procedural justice.

For the total sample only the measure of general attitude toward the Open Door was available, because of the lack of concrete experience with the Open Door system for these respondents. Still, we found significant positive beta weights for all four equations, ranging from .09 to intent to remain and distributive justice to .42 for procedural justice. The R-squared contributions are also significant in all cases and especially strong for procedural justice (.17). These results provide additional support for hypothesis five. 
Finally, the high relationship between the evaluation of the outcome of the Open Door and the perceived interpersonal justice of the Open Door process $(r=.66)$ confirms hypothesis six.

Procedural justice, distributive justice and satisfaction

For the filers, procedural justice had a positive and significant relationship with distributive justice, as suggested in hypothesis seven. Moreover, procedural justice also had positive and significant relationships with the intent to remain with the organization and higher satisfaction. In addition, the evaluation of the outcome and of the interpersonal interaction (both Open Door specific variables), are positively and significantly related to procedural justice, confirming hypotheses eight and nine.

Distributive justice is positively related to the intent to remain and satisfaction. However, procedural justice has a stronger effect on satisfaction (.45 vs .11), thus supporting hypothesis ten. In turn, satisfaction is strongly and positively related to the intent to remain, supporting hypothesis eleven. The R-squared contributions for the set of general organizational perceptions to the explained variance are all significant and range from .09 for distributive justice to .29 for intent to remain.

Again, these results are confirmed for the total sample. Procedural justice had a strong impact on both satisfaction and distributive justice. Distributive justice is also positive related with intent to remain and satisfaction. As before, procedural justice accounts for more variance in satisfaction than does distributive justice (.52 vs. .09), providing further support for hypothesis ten. Satisfaction had a strong effect on the intent to remain, also providing additional support for hypothesis eleven. R-squared contributions of this set (general organizational perceptions) range from .13 for distributive justice to .35 for the intent to remain. In suns, our variables were able to explain .49 of the variance for the intent to remain.

\section{Discussion}

It was not surprising that those who had a positive personal experience with the Open Door system were more likely to have higher perceptions of fairness. When employees experience such events, it is likely that the event will have an impact on their overall perceptions. We should not discount, however, those perceptions of observers, as illustrated in our total sample. Previous research suggests that perceptions of procedural justice are more likely than distributive justice perceptions to result in increasing broader organizational beliefs (Folger \& Konovsky, 1989; Fryxell, 1992). Our research provides further support for this. For both the sample of filers and the total sample, procedural justice was significantly more related 
to satisfaction than was distributive justice. In turn, satisfaction significantly influenced intentions to remain with the organization.

The logic is quite straightforward. Whether individuals actually file a complaint or not, they are often aware of the processes and outcomes that occur in an organization, especially in a potentially critical area such as complaint systems. Moreover, perceptions of procedural fairness may accrue, allowing employees to accept occasional unfavorable outcomes. Therefore, employees' overall perceptions of procedural fairness are formulated as a result of using procedures, observing procedures, and a combination of both. And, these perceptions often translate into other attitudes or beliefs, such as general satisfaction. For an examination of types of procedures that lead to fairness of complaint systems in general, see the Blancero \& Dyer article in this same issue.

Organizations cannot control outcomes. Actual outcomes may be positive or negative for individual employees, depending on the circumstances. Realistically, there are going to be times when employees are unhappy with outcomes and feel that they were not treated fairly. Even in the best managed organizations, mistakes are made and an employee can be treated unfairly. However, by building a solid reputation as an organization with fair procedures, an organization can effectively manage these impressions of fairness.

\section{Implications}

Our research suggests that those individuals who are likely to remain with their organization are those who perceive that they have been treated fairly and have high levels of satisfaction. Moreover, those who had positive complaint incidents were likely to have increased perceptions of fairness. An important lesson is that complaint systems have broader effects than just specific cases. In our full sample, those who had positive attitudes or beliefs toward the Open Door system, whether they used it or not, had higher perceptions of fairness. This strongly suggests that organizations need to be careful to establish fair procedures for complaint systems. As suggested above, while organizations cannot control outcomes, they can control processes. By insuring that a process if fair, an organization can better satisfy and retain their key employees.

Our results are still open to a different interpretation. The strong relationship between positive attitudes towards Open Door and higher perception of fairness could also be due to the fact that employees who think the workplace is fair tend to impose that view on specific programs, such as Open Door systems. This question about the direction of the causal relationship can not be answered based on our data, but has to be explicated by future longitudinal research. 
Another implication of this research deals with the data collection instrument itself. As we discussed early in this paper, most organizations have employee attitude surveys of some type. By collaborating with academic researchers, organizations may be able to uncover more information than they previously have. These data used for this article were used in a collaborative effort with a research director, a human resource director and researchers from CAHRS. Only after discussion among all the parties involved could we have developed this research. We think that use of employee opinion or attitude surveys may have a multitude of untapped information. Note, however, that there are other forms of collaboration that provide different perspectives, or that may help to answer different questions. Cross sectional data, for example, collected from multiple organizations, can provide results that are generalizable and not merely specific to one organization. CAHRS researchers had the opportunity to collaborate with sponsors in another study that examined complaint systems using such a methodology. See the Blancero \& Dyer article in this issue for the results of that study.

Finally, although we've investigated outcomes of fairness, we have not discussed what actually effects fairness perceptions. We know that ensuring fairness in complaint systems can help managers avoid needless problems such as employee turnover and decreased employee commitment and loyalty. Fair systems appear to enhance employee fairness perceptions, which in turn enhance employee attitudes, which lead to lower tendencies to leave. Thus, maintaining a committed and stable work force is, in part, achieved by ensuring that complaint and other systems are viewed as fair. Research and theory suggest how to accomplish this.

Research on fairness, specifically procedural justice, has been increasing over the past twenty years and can be very helpful in designing and evaluating the fairness of organizations policies and practices. There are six procedural rules that can be used to evaluate procedural justice (Leventhal, 1980). These include: (1) consistency -- procedures should be consistent across people and across time, (2) bias suppression -- self interest, or bias, should be avoided in the process, (3) accuracy -- all decisions should be based on accurate information, (4) correctability -- there needs to be an appeal system or mechanism to appeal decisions, (5) representativeness -- the process should be reflective of the issues and concerns of all involved, and (6) ethicality -- the process should maintain ethical standards. We would add two additional rules to this group, using interactional justice. As elaborated by Greenberg (1994), interactional justice can be further broken down into interpersonal justice, which is the degree of sensitivity and concern showed an individual and informational justice, which is the adequacy of the information provided. Thus, we would add: (7) interpersonal sensitivity -- showing a high degree of sensitivity, respect and concern toward employees and (8) adequacy of information -providing 
adequate and timely information. We think these additions are critical. If these eight criteria can be met, a complaint procedure (or any procedure) will be more likely to be perceive as fair.

\section{Conclusion}

In conclusion, the importance of a fair complaint system cannot be overstated. Those who use the system will likely aid in "spillover" ---- "filers" talking about their experiences, either positive or negative, with other employees. Whether a first hand user or an observer, complaint systems affect fairness perceptions. Fairness perceptions, in turn, affect other attitudes and beliefs among employees.

We would like to encourage organizations to collaborate with academic researchers in continuing to uncover valuable information via the use of employee attitude surveys. These data collection instruments may have a lot of untapped knowledge that can be of value both practically and theoretically. We suggest that future research on the issues discussed in this paper are best studies in a collaborative effort. While academic researchers can analyze data and provide theory and models to explain relationships, without the reliable data and practical insights of managers in organizations, we may be missing a valuable perspective. 


\section{References}

Alexander, S. \& M. Ruderman. 1987. The role of procedural and distributive justice in organizational behavior. Social Justice Research, 1: 177-198.

Aram, J.D. \& P.F. Salipante. 1981. An evaluation of organizational due process in the resolution of employee/employer conflict. Academy of Management Review 6,2:197-204.

Arnold, H.J. \& D.C. Feldman. 1982. A multivariate analysis of the determinants of job turnover. Journal of Applied Psychology, 67:350-360.

Balfour, A. 1984. Five types of nonunion grievance systems. Personnel, 67-76.

Bies, RJ. \& J. S. Moag. 1986. Interactional justice: Communicating criteria of fairness. In Research on negotiation in organizations, Vol. 1. Greenwich, CT: JAI Press, 43-55.

Bies, RJ. \& D.L. Shapiro. 1988. Voice and justification: Their influence on procedural fairness judgments. Academy of Management Journal, 31:676-685.

Blancero, D. 1992. Non-union grievance systems: Perceptions of fairness. Proceedings of the 44th annual meeting of the Industrial Relations Research Association. Madison, WI:IRRA, 458-464.

Bluedorn, A.C. 1982. A unified model of turnover from organizations. Human Relations, 35:135-153.

Borofl; KE. 1994. Nonunion grievance procedures: Quantifying the relative superiority of collective voice over individual voice. Paper presented at the 7th annual meeting of the International Association of Conflict Management, Eugene, Oregon.

Borofl; KE. 1991. Measuring the effectiveness of a workplace complaint system In D. Lipsky, D. Sockell and D. Lewin, eds., Advances in Industrial and Labor Relations. Greenwich, CT: JAI Press, 207-233.

Dailey, RC. \& D.J. Kirk. 1992. Distributive and procedural justice as antecedents of job dissatisfaction and intent to turnover. Human Relations, 45,3:305-317.

Delaney, J. T.; Lewin, D. \& C. Ichniowski. 1989. Human resource policies and practices in American firms, BLM \#137. Washington, D.C.:USDOL.

Employee Responsibilities and Rights Journal. 1994. Special issue: Managerial third party dispute resolution, vol. 7, number 1, March.

Ewing, D.W. 1989. Justice on the job: Resolving grievances in the nonunion workplace. Boston: Harvard Business School Press.

Folger, R 1977. Distributive and procedural justice: Combined impact of "voice" and improvements on experienced inequity. Journal of Personality and Social Psychology, 35: 108-119. 
Folger, R \& J. Greenberg. 1985. Procedural justice: An interpretive analysis of personnel systems. In K Rowland and G. Ferris, eds., Research in Personnel and Human Resource Management, Vol. 3:141-183. Greenwich, CT: JAI Press.

Folger, R \& M. Konovsky. 1989. Effects of procedural and distributive justice on reactions to pay raise decisions. Academy of Management Journal, 32,1:115-130.

Fryxell, G.E. 1992. Perceptions of justice afforded by formal grievance systems as predictors of a belief in a just workplace. Journal of Business Ethics, 11:63 5-647.

Fryxell, G.E. \& M.E. Gordon. 1989. Workplace justice and job satisfaction as predictors of satisfaction with union and management. Academy of Management Journal, 32:851-866.

Greenberg, J. 1987. Reactions to procedural injustices in payment distributions: Do the means justify the ends? Journal of Applied Psychology, 72:55-61.

Greenberg, J. 1990a. Organizational justice: Yesterday, today and tomorrow. Journal of Management, 16:399-432.

Greenberg, J. 1990b. Employee theft as a reaction to underpayment inequity: The hidden costs of pay cuts. Journal of Applied Psychology, 75,5:561-568.

Greenberg, J. 1993. The intellectual adolescence of organizational justice: You've come a long way, maybe. Social Justice Research, 6,1:135-147.

Greenberg, J. 1994. Using socially fair treatment to promote acceptance of a work site smoking ban. Journal of Applied Psychology, 79:288-297.

Hollenbeck, J.R \& C.R Williams. 1986. Turnover functionality versus turnover frequency: A note on work attitudes and organizational effectiveness. Journal of Applied Psychology, $71: 606-611$.

Joereskog, K G. \& D. Soerbom. 1989. LISREL 7: A guide to the program and applications (2nd. ed.). Chicago: SPSS.

Klaas, B. S. \& D.C. Feldman. 1994. The impact of appeal system structure on disciplinary decisions. Personnel Psychology, 47:91-108.

Lee, T.W. \& RT. Mowday. 1987. Voluntarily leaving an organization: An empirical investigation of Steers and Mowdays model of turnover. Academy of Management Journal, 30:721-743.

Leventhal, G. 1980. What should be done about equity theory? In KT. Gergen, M. S. Greenberg, \& RH. Willis (eds.) Social Exchange: Advances in Theory and Research, pp. 27-55. New York: Plenum Press.

Lind, E.A.; Kanfer, R \& P.C. Earley. 1990. Voice, control, and procedural justice: Instrumental and non-instrumental concerns in fairness judgments. Journal of Personality and Social Psychology, 59:952-959. 
Lind, E.A. \& Tyler, T. 1988. The social psychology of procedural justice. New York: Plenum

Lind, E.A.; Walker, L.; Kurtz, S., Musante, L. \& J.W. Thibaut. 1980. Procedure and outcome effects on reactions to adjudicated resolution of conflicts of interest. Journal of Personality and Social Psychology, 39:643-653.

McCabe, D.M. 1988. Corporate non-union complaint procedures and systems. NY: Praeger.

Michaels, C.E. \& D.E. Spector. 1982. Causes of employee turnover: A test of the Mobley, Griffeth, Hand \& Meglino model. Journal of Applied Psychology, 67:53-59.

Mobley, W.H. 1982. Employee turnover: Cause, consequences and control. Reading, Mass: Addison-Wesley Publishing, 1982.

Moorman, RH. 1991. Relationship between organizational justice and organizational citizenship behaviors: Do fairness perceptions influence employee citizenship? Journal of Applied Psychology, 76:845-855.

Moorman, RH., B.P. Niehoff, \& D.W. Organ. 1993. Treating employees fairly and organizational citizenship behavior: Sorting the effects of job satisfaction, organizational commitment, and procedural justice. Employee Responsibilities and Rights Journal, 6,3:209-226.

Peterson, RB. 1994. Organizational governance and the grievance process: In need of a new model for resolving workplace issues. Employee Responsibilities and Rights Journal, 7,1:9-22.

Peterson, RB. \& D. Lewin. 1990. The non-union grievance procedure: A viable system of due process? Employee Responsibilities and Rights Journal, 3,1:1-18.

Porter, L.W. \& RM. Steers. 1973. Organizational work and personal factors in employee turnover and absenteeism. Professional Psychology, 4:151-176.

Rowe, M.P. \& M. Baker. 1984. Are you hearing enough employee concerns? Harvard Business Review, 62:127-135.

Scarpello, V. \& J. P. Campbell. 1983. Job satisfaction: Are all the parts there? Personnel Psychology, 35:577-600.

Schaubroeck, J., D.R May \& F.W. Brown. 1994. Procedural justice explanations and economic hardship: A field experiment. Journal of Applied Psychology, 79,3:455-460.

Steel, RP. \& N.K Ovalle. 1984. A review and meta analysis of research on the relationship between behavioral intentions and employee turnover. Journal of Applied Psychology, 69:673-686.

Tett, RP. \& J.P. Meyer. 1993. Job satisfaction, organizational commitment, turnover intention, and turnover: Path analyses based on meta-analytic findings.

Westin, A.F. \& A.G. Feliu. 1988. Resolving employment disputes without litigation. Washington, D.C.:BNA. 